\title{
Moral Intuition, Social Sin, and Moral Vision: Attending to the Unconscious Dimensions of Morality and Igniting the Moral Imagination
}

\author{
Elizabeth Sweeny Block
}

Citation: Block, Elizabeth Sweeny. 2021. Moral Intuition, Social Sin, and Moral Vision: Attending to the Unconscious Dimensions of Morality and Igniting the Moral Imagination. Religions 12: 292. https://doi. org/10.3390/rel12050292

Academic Editor: Dafydd Mills Daniel

Received: 16 February 2021

Accepted: 2 April 2021

Published: 22 April 2021

Publisher's Note: MDPI stays neutra with regard to jurisdictional claims in published maps and institutional affiliations.

Copyright: (C) 2021 by the author Licensee MDPI, Basel, Switzerland. This article is an open access article distributed under the terms and conditions of the Creative Commons Attribution (CC BY) license (https:// creativecommons.org/licenses/by/ $4.0 /)$.
Department of Theological Studies, Saint Louis University, St. Louis, MO 63103, USA; elizabeth.block@slu.edu

\begin{abstract}
This paper argues that the unconscious dimensions of the moral life-for example, moral vision, moral imagination, and distorted consciousness-are some of the most urgent provinces of moral theology today. Historically, moral theology was concerned with moral quandaries and observable actions, and moral agents were understood to be rational, deliberate, self-aware decision makers. Cultures of sin, such as racism and sexual violence, require that moral theologians reconceive of moral agency. Confronting these unconscious dimensions of the moral life requires integrating research in disciplines such as science, sociology, history, and anthropology with Christian ethics, pushing the boundaries of what has traditionally been understood to be the domain of moral theology. As an example, this paper draws upon the mutually reinforcing theories of moral intuition, developed by social and moral psychologists, and recent theories of social sin in Christian ethics, arguing that attention to the unconscious province of the moral life is necessary for developing an accurate conception of moral agency and for future work in moral formation. This paper concludes with a modest proposal for how stories might enable awareness of our distorted consciousness.
\end{abstract}

Keywords: Jonathan Haidt; intuition; moral imagination; moral vision; narrative; racism; sexual violence; social sin

\section{Introduction}

Pockets of scholarship in recent decades have called attention to the need to alter existing conceptions of moral agency. Philosophers and religious ethicists writing about technology, the environment, and racism, for example, demonstrate the inadequacy of traditional conceptions of moral agency-in which human beings are understood to be rational, deliberate, self-aware decision makers-in the face of the magnitude of global moral challenges today. In the 1970s, Philosopher Hans Jonas asserted that the scope and reach of technological innovation necessitated new ways of doing ethics and conceiving of the person as moral agent. Whereas ethics was once confined to the here and now, Jonas argued that novel technology increases the power and scope of human agency such that the sphere of "neighbor ethics" and the concept of responsibility are inadequate given human impact on and duty to the future (Jonas 1973). William Schweiker's work on responsibility calls awareness to the radical extension of human power and its impact on individual action (Schweiker 1995). Recent scholarship in critical race theory has illuminated White persons' participation in unconscious racism and White privilege and called for expanded conceptions of responsibility to hold persons accountable not only for explicit acts of racism, but also, and perhaps even more importantly, for implicit racism and unconscious racial bias ((Applebaum 2010); see also (Massingale 2010)). Environmental ethicists have observed the ways that the scope of climate change problematizes human agency. Willis Jenkins contends that agents experience moral incompetence in the face of climate change, while Sarah Fredericks argues that climate change requires developing concepts of collective agency and responsibility, as well as collective apology (Jenkins 2013b; 
Fredericks 2019). These examples illustrate that moral agency must extend well beyond individual rationality and the seemingly straightforward choice to do good or harm.

Scholarship outside of philosophy and religious ethics provides an important source for modifying conceptions of human agency. Advances in psychology, anthropology, and even behavioral economics reveal the ways that religious ethicists can benefit from interdisciplinary dialogue that contributes to more accurate depictions of moral action. Patrick McKearny argues that the empirical descriptions of social anthropology may have a role to play in moral judgment, despite the complex relationship between description and judgment. To bring the fields of anthropology and ethics together is to ask the question, "How can we attend faithfully to the complexity of the world while still acting in it?" (McKearny 2016, p. 567). He argues that an anthropology of ethics brings to religious ethics attention to varieties of ethical subjectivity, that is, attention to the importance of description for religious ethics. Maria Heim and Anne Monius highlight the contributions that cultural and linguistic anthropologists make to the study of ethical experience and concerns in everyday life. Anthropologists importantly attend to empirical ethics, what human beings are actually like (Heim and Monius 2014, p. 386). Christina McRorie attends to insights from the behavioral sciences that disrupt the rational model of homo economicus. Behavioral economists, she observes, are doing descriptive moral anthropology, raising questions about freedom, agency, and identity that are valuable for the work of religious ethicists. McRorie identifies contributions from behavioral economics that include recognition that humans do not actually weigh costs and benefits in a linear or mathematical manner and our thoughts and behaviors are influenced by the environment of the moment and by stimuli of which we are not conscious (McRorie 2016, pp. 199-200). She concludes that religious ethicists would benefit from being more attentive to empirical data about the complexity of human decision making that challenge simplistic accounts of human nature. This kind of knowledge, says McRorie, can begin to enable us "to change the conditions we find ourselves in when we decide these conditions do not adequately empower the kind of agency we would prefer" (McRorie 2016, p. 219). Empowered with knowledge from the behavioral sciences, we can begin to interact with our economic environments "more advisedly" (McRorie 2016, pp. 219-20).

Religious ethicists have good reason to believe that our model of the human being as an entirely rational, self-aware decision maker is neither entirely accurate nor advisable. Both the magnitude of the moral challenges we face today and the contributions of disciplines outside of religious ethics point to the need to reconceive of moral agency and the related project of moral formation. Although scholars in the fields of anthropology, psychology, behavioral economics, and critical race studies acknowledge that moral decision making is impacted by unconscious factors, our churches, schools, and religious ethical methods for forming moral agents are lagging. It has long been the case that the Catholic church forms individuals to make deliberate, discrete moral decisions as individual agents and teaches people that they are not responsible for the effects of their actions that they did not choose or could not avoid. Consider this description of the human person in the Catechism of the Catholic Church: "God created man a rational being, conferring on him the dignity of a person who can initiate and control his own actions" (Catechism of the Catholic Church 1992, p. 1730). The Catechism defines moral freedom as "the power, rooted in reason and will, to act or not to act, to do this or that, and so to perform deliberate actions on one's own responsibility" (Catechism of the Catholic Church 1992, p. 1731). Additionally, the Catechism describes conscience as "a judgment of reason whereby the human person recognizes the moral quality of a concrete act that he is going to perform, is in the process of performing, or has already completed. In all he says and does, man is obliged to follow faithfully what he knows to be just and right" (Catechism of the Catholic Church 1992, p. 1778). Consider also the description of prudence offered in the United States' Catholic Bishops' guide to voting, Forming Consciences for Faithful Citizenship: "Prudence shapes and informs our ability to deliberate over available alternatives, to determine what is most fitting to a specific context, and to act decisively" (United States 
Conference of Catholic Bishops 2019, p. 19). The Catholic church continues to rely on a conceptual framework that prioritizes reason, knowledge, and explicit, decisive action while it neglects agents' unconscious formation in cultures of sin. Bryan Massingale observes that conscience formation in the Catholic church is inadequate because it does not account for "our captivity to value systems contrary to the gospel" and is "dependent upon the conscious awareness and intentions of the moral agent". ${ }^{1}$

Joining with those scholars who take seriously the need for accurate description, I argue that Christian ethics must account for the work of moral psychology in order to see that Christian ethicists must turn their attention to shaping moral intuitions in response to the problem of captivity to cultures of sin. Moral psychology is "systematic inquiry into how morality works" and how persons actually live their moral lives (Liao 2016, p. 1). It draws on various subdisciplines of psychology as well as neuroscience, sociology, anthropology, and philosophy to explore how moral agents function as such, including inquiry into the human capacity to make and act on moral judgments. This paper takes as its starting point moral intuitionist theory, a prominent theory in moral psychology which holds that moral intuitions, including moral emotions, play a central role in our moral lives. I do not set out to prove this to be true. Rather, I aim to show that the concept of "social sin," as defined by Christian ethicists, is compatible with the idea that our moral judgments and responses are formed by more than ratiocination and that sometimes these "intuitions" are formed by distorting or deforming cultures. The concept of social sin also enhances intuitionist theory by illuminating how moral intuitions affect moral responsiveness in relation to more than individual wrongdoing. Intuitionist theory supports recent work in Christian ethics on the unconscious dimensions of injustice, reinforcing the need to continue addressing implicit discrimination and marginalization that so many in positions of privilege struggle even to see, let alone remedy. ${ }^{2}$ Together, moral intuition and cultures of sin point to the inadequacy of models of moral agency that rely on the rational decision maker to recognize and make decisions that oppose injustice.

Christian ethicists have recently described the social sins of sexual violence and racism as cultures of $\sin$, constituted not by isolated individual actions, but by social conditions and patterns that enable perpetrators of sexual violence and racism. The category of social sin calls our attention to unconscious distortions in our moral perception that prevent us from seeing injustice and our own participation in it; in this way, recent scholarship on social sin and cultures of sin share in common with moral intuitionism a focus on the unconscious dimensions of our moral life. ${ }^{3}$ Moral intuitionism is useful in calling us to attend to what we do not or cannot see-not explicit acts of wrongdoing, but the distorted culture and perception that sustain injustice. Awareness of moral intuitions invites us to attend to the background tenor of our responsiveness or reactivity, and so alerts us to something at work in us-a source of moral judgment-of which we are typically not conscious. While intuitionist theory is intended to be descriptive (whether it is successful in avoiding normativity is another matter), the category of social sin names our responsibility. At the same time, the culture of sin points to the need for moral psychologists to think beyond personal actions, considering more than merely isolated and artificial moral dilemmas, such as the well-known trolley problem. Ultimately, I argue, even if one is not willing to go as far as social intuitionist Jonathan Haidt in claiming that moral judgments are almost exclusively constituted by intuitions, the shared unconscious domain of moral intuitionism and social sin points to the need for Christian ethicists to focus our work and teaching on making the unconscious conscious and on correcting and enhancing moral perception. The unconscious dimensions of the moral life and the seemingly acceptable actions that in fact perpetuate injustice constitute the province of moral theology that most needs attention today.

I will make this argument in three steps. First, I will draw on the research of moral psychologists, including Jonathan Haidt, Joshua Greene, and Peter Ditto and Brittany Liu, to review the salient features of moral intuitionist theory, which holds that persons make intuitive, non-conscious moral judgments. ${ }^{4}$ Recent scholarship on moral intuitions 
includes recognition of differences in the ways we intuitively hold others responsible for actions verses omissions and suggests that our intuitions shape our interpretation of the facts of a situation, both of which have concrete implications for making normative Christian ethical claims. Importantly, this empirical data describes the very problems Christian ethicists must address: our failure to hold ourselves and others accountable for injustices that we can claim we did not "cause" and our tendency to interpret facts to match our intuitions, thereby not necessarily taking into account the full truth of a situation. Second, I will draw on recent scholarship that describes social sin as a culture and show that it reinforces the intuitionists' recognition of an unconscious dimension of morality, illuminates the significance of the social conditions and patterns that shape our intuitions, and highlights the urgent need to attend to the quality of our moral vision. Moral vision is the implicit lens through which we view the world and one another and which either enables our recognition of injustice or hinders it. Finally, all too briefly, I will suggest that the immediate work of teachers and practitioners of Christian ethics is, therefore, to expand moral imaginations in order to form persons' moral vision and that one avenue for this is story.

\section{Moral Intuitionism}

In recent decades, the dominant perspective in moral psychology has shifted from the rationalist view that moral decision making is comprised of deliberative reasoning and relies on explicit principles, the position famously represented by Lawrence Kohlberg, to a view that prioritizes the role of emotion and intuition in moral judgments (Kohlberg 1969). Most notably, Jonathan Haidt introduced his social intuitionist model of moral judgment in 2001, which holds that "moral intuitions (including moral emotions) come first and directly cause moral judgments" (Haidt 2001, p. 814). According to Haidt, intuition and reasoning are two different modes of cognition. Appealing to Plato, Kant, and Kohlberg as well as contemporary moral psychologists, Haidt defines moral reasoning as "conscious mental activity that consists of transforming given information about people in order to reach a moral judgment" and is "intentional, effortful, and controllable ... the reasoner is aware that it is going on" (Haidt 2001, p. 818). He compares moral reasoners to scientists who form and test hypotheses in a multi-step process. In contrast, moral intuition is "the sudden appearance in consciousness of a moral judgment, including an affective valence (good-bad, like - dislike), without any conscious awareness of having gone through the steps of searching, weighing evidence, or inferring a conclusion" (Haidt 2001, p. 818). Haidt and other intuitionists use affectively charged events-incestuous siblings or eating one's pet dog-to demonstrate the plausibility of the intuitionist model. Haidt conducted his own studies and also relied on neuroimaging studies that showed moral decision making involves regions of the brain associated with emotions. Presenting subjects with a story of incestuous siblings, Haidt found that most people quickly regarded their actions as immoral but could not provide justification for this position. "In the social intuitionist model," Haidt tells us, "one feels a quick flash of revulsion at the thought of incest and one knows intuitively that something is wrong" (Haidt 2001, p. 814). It is only after the fact that one engages in moral reasoning in order to articulate what one already knows to be the case intuitively. Haidt does not, therefore, reject moral reasoning but believes it is secondary, utilized only when there is conflict between competing moral intuitions or when one needs to explain one's beliefs to others. He also makes clear that his claim is descriptive, not normative; he is not arguing that this is how moral judgments ought to be made, but rather demonstrating that this is how moral reasoning works.

Haidt calls his model not just intuitionist but social because he identifies moral judgment - that is, evaluations of the actions or character of a person made with respect to a culture's virtues-as an interpersonal process. The moral reasoning of other people, following their intuitions, impacts the intuitions of others. "Reasoned persuasion works not by providing logically compelling arguments but by triggering new affectively valenced intuitions in the listener" (Haidt 2001, p. 819). Additionally, the moral judgments of 
others-friends, allies, acquaintances-influence us, even without reasoned persuasion. Other people's moral judgments may either elicit in us outward conformity or simply influence our privately held judgments. Haidt observes, "Ever since Plato wrote his Dialogues, philosophers have recognized that moral reasoning naturally occurs in a social setting, between people who can challenge each other's arguments and trigger new intuitions" (Haidt 2001, p. 820).

In this paper, I take seriously the social intuitionist model, recognizing, however, that the precise relationship between reason and emotion in morality is far from settled (and need not be resolved for the purposes of this essay). A number of scholars agree partially with Haidt but leave more room for the role of reason or see reason and emotion as less diametrically opposed than Haidt. None of them eradicates the role of intuition; rather, they nuance it, and so their counter-positions do not eliminate the need for ethicists to contend with moral intuitions. ${ }^{5}$

Joshua Greene is a collaborator of Haidt's but favors a dual-process theory of moral judgment as opposed to the intuitionist theory. In this model, "moral judgment is influenced by both automatic emotional responses (automatic settings) and controlled, conscious reasoning (manual mode)" (Greene 2016, p. 121). Greene argues that these different "settings," manual and automatic, which he likens to the settings on a digital SLR camera, are better and worse at different things and are, therefore, both necessary at different times. For the automatic setting to work well, it must be "shaped by trial-and-error experience," which includes genetic predisposition, cultural transmission, and learning from personal experience (Greene 2016, p. 131). In contrast, unfamiliar problems-"ones with which we have inadequate evolutionary, cultural, or personal experience"-require manual mode, so to speak (Greene 2016, p. 131). According to Greene, we must rely more on conscious, controlled reasoning when we are dealing with problems with which we have inadequate experience; "it would be a cognitive miracle if we had reliably good moral instincts about unfamiliar moral problems" (Greene 2016, p. 131). He labels this conclusion "the No Cognitive Miracles Principle" (Greene 2016, p. 131).

However the dynamic is conceived, it is clear that emotions and intuitions play an important role in moral judgments, even if the jury is still out on the precise relationship between the two and whether one has primacy over the other. If emotions and intuitions play a central role in our moral lives, and we do not always or often engage in rational, deliberate, calculated decision making, then these insights should profoundly impact the work of Christian ethics. Moral intuitionists draw our attention to automatic processes that do not in fact have to yield irresolvable conflict between reason and emotion. Being descriptively accurate and seeking to understand the intuitions that drive disagreement about the good are essential tasks for the enterprise of ethics. Moral psychologists are typically occupied with studies that expose various populations to moral dilemmas but rarely do moral psychologists study how people naturally arrive at their moral judgments, especially when those judgments clash with the communities around them (Bloom 2012, p. 86). Moral intuitions provide important insights into moral disagreements, which is of critical importance if we have any hope of making progress on violence, climate change, racism, and other large-scale moral problems that span the globe.

Haidt's moral intuition theory focuses on examples where we intuitively know that something is obviously wrong to people of our culture, such as eating a pet dog or engaging in an incestuous sexual relationship. A kind of "yuck factor" kicks in that informs our moral judgment. What about situations that ought to evoke a "yuck" from moral agents but do not? Haidt assumes that moral agents will be appropriately horrified by moral wrongs, yet examples abound of moral wrongs that do not elicit this kind of horror, especially when the wrongs are more systematic and less explicit. Christian ethicists studying social sin demonstrate that our intuitions function problematically and unjustly. Our unconscious moral processes prevent us from seeing the wrongs of racism and sexual violence in our communities and cultures and in all likelihood contribute to these cultures of sin. Intuitions do not just lead us to recognize what is right; they may very well perpetuate what is unjust. 
Haidt does not address this problem. Before turning to Christian ethicists' contributions to the study of social sin, I consider two further insights of moral intuitionists which likewise suggest where intuitions can lead us astray: we intuitively judge failures to act to be less harmful than direct actions, and we interpret the facts of a situation so that they cohere with our previously held intuitions.

\section{Moral Intuitions, Culpability for Harm, and Facts}

Two additional insights about moral intuitions presented by moral psychologists are worthy of consideration. First, scholars have shown that the moral distinction between active and passive harm has a significant influence on people's moral judgments. Consider this non-moral example. John "rolls a ball toward twelve pins (an action), and Jane ... stands by and allows the ball to roll (an omission). John might be considered more causally responsible for the pins' falling than Jane is and also to have intended the pins to fall more than Jane did" (Cushman and Greene 2012, p. 37). Now imagine that the ball knocks over not twelve pins but an innocent child, and "John looks more culpable than Jane because he appears to have directly caused the child harm and intended the harm more than Jane" (Cushman and Greene 2012, p. 38). Cushman and Greene cite experimental evidence that supports the hypothesis that "people assign more causal responsibility to actions than to omissions, and they are more likely to consider actions intentional" (Cushman and Greene 2012). A study using functional neuroimaging to infer the cognitive processes underlying the distinctions people make between actions and omissions showed that "automatic psychological mechanisms robustly condemn actions but not omissions" (Cushman and Greene 2012, p. 39). We automatically and intuitively judge actions harmful but not necessarily omissions. Cushman and Greene assert that "the evidence suggested that additional controlled, cognitive processing is necessary to equate harmful omissions with harmful actions. The automatic processes that support the judgment of harmful actions appear to be insufficient for the condemnation of harmful omissions" (Cushman and Greene 2012, p. 40). In other words, we do not intuitively hold someone accountable for a harmful omission the way we do a harmful action.

Another startling piece of scholarship suggests that people tend to bring their factual beliefs into line with their moral intuitions. Observing that moral judgments have a complicated relationship to descriptive facts, Peter Ditto and Brittany Liu argue that "people are both moral intuitionists and moral realists: that our beliefs about right and wrong are more often a product of affective reactions than of deliberative cognitive processing, but that we nonetheless feel a need to justify the 'truth' of our moral beliefs with reference to some form of evidence" (Ditto and Liu 2012, p. 51).

Based on a variety of empirical studies, Ditto and Liu conclude that "because of our desire to reify our moral intuitions - to transform them into moral 'beliefs' that can be right or wrong in the same sense that factual beliefs can be right or wrong-we tend to shape our descriptive understanding of the world to fit our prescriptive understanding of it" (Ditto and Liu 2012, p. 65). For instance, an individual who favors the death penalty is reassured by the belief that capital punishment serves as a deterrent to future crime, while someone who is opposed to the death penalty on principle will nevertheless "come to believe that capital punishment is ineffective at deterring murder" (Ditto and Liu 2012, p. 58). The authors cite another study, which demonstrates that moral values can shape factual beliefs, in which "those least likely to support mandatory HPV vaccinations also thought it was least likely to be effective in producing benefits and most likely to have undesirable costs" (Ditto and Liu 2012, p. 59).

These claims have important consequences. Unconscious biases are constituted by these kinds of omissions and the ways we interpret the facts of a situation. If someone is not directly responsible for causing harm through their action, we are much more likely to fail to see them as responsible for the harm caused by failing to act. This permits people to ignore racial injustice and not be held accountable because they did not commit an explicit, overt act of racism. Sexual violence, climate change, and gun violence are also prime 
examples. In the United States, we continue to fail to pass common sense gun safety laws, despite the horrific frequency of mass shootings. We fail to see that the ways we talk about women and LGBTQ+ persons when we think we are "joking" has real consequences for a culture of sexual violence where people's bodies are violently controlled and dominated. If someone is not out there actively dumping waste into the ocean, then is she not accountable for climate change? It would seem, based on Cushman and Greene's study, that we do not intuitively make the important connections between our omissions-not voting in local elections, not striving to eliminate one's own use of plastics, not walking or riding the bus when we are able-and the harms done to our planet and our fellow humans. Although these actions are not the immediate or sole causes of climate change or gun violence, they do make an impact. Cushman and Greene have shown that unless a person is the immediate and direct cause of some harm, he is not likely to connect other failures, more removed from immediate causation, to the harms of climate change, racism, and sexual violence. Willis Jenkins, writing about the future of ethics and climate change in particular, contends that "human brains are not adapted to resolve moral problems with such abstract causation, inherent uncertainty, and extensive scales of space and time" (Jenkins 2013a, p. 70). Climate change was not set in motion by the current generation yet requires action by the current generation to mitigate the serious effects that will fall on future generations; this makes holding anyone responsible a grave challenge. Jenkins observes, for example, that negotiators from the Global North "see climate change as an unforeseen side effect of benign economic development" (Jenkins 2013a, p. 73). Moral psychologists confirm Christian ethicists' fears about the avoidance of responsibility.

If we interpret the facts of a situation to match our moral intuitions, as Ditto and Liu claim, we are in real trouble. Again, in his work on climate change, Jenkins describes "alternative views of reality" wherein different groups understand the causes of climate change very differently. "How do we develop cooperation," he asks, "amid foundational disagreements over globalization and inequality?" What we believe to be the facts of a situation are inseparable from our moral vision, the lens through which we view the world. In the United States, it is almost impossible to think of the interpretation of facts without the Trump presidency coming to mind. His proclivity for declaring falsehoods as truths was a hallmark of his presidency (Kessler et al. 2019). Moreover, his supporters were and continue to be unfazed by his lies (see, for example, (Cillizza 2019)). It is a minor relief to know, as Ditto and Liu observe, that generally speaking, "people do not ignore plausible information to believe whatever they wish to believe just because they wish to believe it," and so-called "motivated reasoning processes are most pronounced when information is ambiguous or contradictory," but they also note that this ambiguity describes the situation around "virtually every judgment humans make" (Ditto and Liu 2012, p. 58 n1). In other words, one's moral vision shapes one's understanding of the facts of a situation, especially when there is ambiguity, which means people end up with distorted views of the facts. Those who believe that wearing masks during the COVID-19 pandemic limits their liberty will interpret the facts and data about mask wearing as it relates to the spread of COVID-19 differently than those whose moral vision embraces science.

The descriptive work of moral psychologists like Haidt and Greene can and should inform the work of Christian ethicists, who need to attend to the fact that moral judgments are often made on the basis of intuitions and emotions. Moral psychology contributes to Christian ethics an attentiveness to empirical data, and it challenges purely rational and overly simple descriptions of moral decision making and moral agency. Moral intuitionist theory points to the ways we are formed and conditioned long before we meet a moral challenge that requires a decision. It is a reminder that Christian ethics cannot simply reason its way to justice; we must also attend to the province of the unconscious dimensions of the moral life, including the lens through which we perceive the world around us. Christian ethics must target perception and awareness, the implicit dimensions of the moral life. 


\section{Intuition, Ignorance, and the Distorted Consciousness of Social Sin}

It is unsettling how clearly research on moral intuition coheres with recent scholarship by Christian ethicists on social sin. Kristin Heyer, relying on the distinction between personal sin and the sin of the world in Catholic moral theology, defines social sin broadly as "the unjust structures, distorted consciousness, and collective actions and inaction that facilitate injustice and dehumanization" (Heyer 2012, p. 37). Heyer is concerned with unmasking "the nonvoluntary dimension of social sin" and, in the case of her own research, "the ideological and subconscious dynamics at play in resisting hospitality to immigrants." She notes that a focus on sin as personal action cannot adequately account for what is nonvoluntary (Heyer 2012, p. 42). This concern with what is beneath our consciousness or what arises from distorted consciousness should give us pause in light of moral intuitionist theory. If we make decisions intuitively, without conscious deliberation, and Christian ethicists have identified aspects of social sin as unconscious and nonvoluntary, then there is good reason to worry about the formation of intuitions in cultures of sin. Cultures of racism and sexual violence are illustrative of this, so I turn briefly to each.

Megan McCabe argues that sexual violence is a problem for social ethics. Her work makes the case that we ought not only be concerned with adjudicating "particular instances of rape or unjust sex," but also working to transform "the social conditions and patterns that normalize and obscure particular instances of sexual violence" (McCabe 2018, p. 637). Taking sexual violence seriously as a social sin means "it is a situation for which all members of the culture share responsibility." She observes that the problem of rape on university campuses is not a problem of isolated instances of violence; rather, "individual rapes are a manifestation of a broader rape culture that makes rape seem normal" (McCabe 2018, p. 637). Just as important as the range of violence that university students experience are "the beliefs, assumptions, and conversations we all have about gender, sex, violence, and rape itself" (McCabe 2018, p. 638). This sense of shared responsibility for injustice is why Elisabeth Vasko has argued that we must reject the victim-perpetrator binary in favor of an awareness of the community's complicity in violence, where violence is defined as anything that denigrates the personhood of another. In her theology for bystanders, Vasko says we should not be asking, "'Why did you let this happen to you,' or, 'Why did you do this to him,' but, 'Why did we let this happen in our community?'" (Vasko 2015, p. 15). In other words, responsibility lies with the community that enables violence as much as with the perpetrator. As McCabe observes, the scope of the problem is much greater than individual acts of sexual violence; "sexuality in the American context is socially conditioned by violence and gendered expectations regarding women's availability and submission and men's correlative sexual dominance" (McCabe 2018, p. 639). McCabe expands the responsibility associated with individual acts of sexual violence by identifying a culture of violence and misogyny that enables particular acts to occur. Heyer, Vasko, and McCabe all thus call attention to the unconscious dimension of social sin, that which we do not and cannot see because we are so deeply embedded in and formed by sinful cultures.

In much the same way, Bryan Massingale has described racism as a culture, a way of life in which we are so thoroughly immersed that we cannot see it all around us. He contrasts this with what he calls the "common sense" definition of racism: "Person A, usually but not always white, does something negative to Person B (usually but not always black or Latino) because of the color of his or her skin" (Massingale 2010, pp. 1, 13). In contrast to this explicit racism, Massingale identifies a cluelessness in White culture that is profoundly harmful, yet goes unnoticed by Whites. It is worth quoting his descriptions of White culture at length: "The essence of white culture," he tells us, "is a worldview that-when it adverts to itself-sees itself as the measure of what is real, standard, normative, and/or normal ... Because it purports to encompass reality, white culture does not have to be aware of itself unless those who are 'other' challenge its presumption (or pretense) of being normative or standard" (Massingale 2010, p. 22). Similarly, Ibram Kendi defines racism as "the marriage of racist policies and racist ideas that produces and normalizes racial inequities" (Kendi 2019, p. 17). Both Massingale and Kendi highlight the normalization of racism. 
As a culture, racism is "a set of shared beliefs and assumptions that undergirds the economic, social, and political disparities experienced by different racial groups" and "a communal and learned frame of reference that shapes identity, consciousness, and behavior" (Massingale 2010, pp. 24-25). Massingale asserts that racism is predominantly unconscious: it "operates as a negative-yet not conscious, deliberate, or intentional—decision-making factor, due to the pervasive cultural stigma attached to dark skin color in Western culture." This unconscious culture of sin is not necessarily manifested in overt displays of racism and is that much more pernicious because it permeates seemingly neutral or even good actions.

Similarly, philosopher Shannon Sullivan contends that racism manifests physiologically and therefore unconsciously. Sullivan recalls a discussion of stereotypes of African American men in her introductory feminist philosophy course when a White, female student "quickly raised her hand, stood up, and insisted somewhat confrontationally, 'But I am scared of black men! If I pass one on the street at night, I can't help it. I tense up and get knots in my stomach'" (Sullivan 2014, p. 592). Tongue in cheek, Sullivan comments that "nothing is more real and irrefutable than felt physiological responses," therefore this student's "body's alarmed response to black men means that they are frightening" (Sullivan 2014, p. 592). In fact, she contends, her student's reaction is a "physiological symptom of a socio-political problem, not irrefutable evidence of a racially hierarchical reality" (Sullivan 2014, p. 608). Physical symptoms reflect unconscious racial bias and cultures of racism. Sullivan concludes that we need to ask, "how did a white woman's physiology come to be in a state such that her stomach seized up when she saw a black man, and how might her reaction to this and similar situations be changed?" (Sullivan 2014, p. 608).

Sullivan's question is the central concern of this essay. If moral intuition plays a central role in our moral lives, then how do we form unconscious-and in some cases, physiological-intuitions so that they are non-distorting? If intuitions are a part of moral decision making, then ethicists must confront them and offer methods for identifying and rectifying them. Joshua Greene concludes the same at the end of his essay on the limits of intuitive morality, declaring that, "We need to understand the structure, origins, and limitations of our intuitive moral thinking, the better to know when our moral instincts are on target," and, importantly, I add, when they are not (Greene 2016, p. 140).

The social sins of racism and sexual violence have impactful yet unconscious dimensions. The reality is that in the United States, White moral intuition tends to be embedded in a culture of sin, formed by privilege. "We cannot see the forest because the trees are in the way," or so the saying goes. Consider the case of the White Dallas, Texas police officer, Amber Guyger, who shot and killed her black neighbor, Botham Jean, in his own apartment in 2018 when she mistook his apartment for her own and believed him to be an intruder. At her sentencing, Jean's brother embraced Guyger and offered her words of forgiveness, as did Judge Tammy Kemp, also an African American, who gave Guyger her Bible. Many immediate reactions praised the forgiveness and grace on display in that courtroom, but J. Kameron Carter writes,

This week's show of grace and forgiveness toward Guyger, like those before it, requires that we ask some hard questions. What if "grace" and "forgiveness" and their compulsory racialized performance are part of what makes this antiblack world keep on ticking? What if grace and forgiveness work in the interest of antiblackness? And finally, what if grace and forgiveness are part of what must be refused in order to bring to an end an antiblack and brown world? (Carter 2019)

Privileged persons do not see the racism in this scenario because they cannot see it. Most people intuitively find this story to be heartwarming, an instance of forgiveness. Intuition tells us that offering forgiveness is good, yet Americans live in a culture, says Carter, that prizes forgiveness without acknowledging how forgiveness might secure the culture of Whiteness. Carter raises these questions in order to address "how America is structured through race." As Massingale observes, racism functions as a culture and shapes people's moral vision such that they do not even recognize it when it happens. Racism is 
not as simple as conscious, overt, malicious actions. The culture of racism infiltrates our moral intuitions.

The cultures of sin described by Heyer, McCabe, and Massingale also illustrate the need for moral psychologists to broaden their focus beyond individual actions and discrete moral dilemmas. Yu, Siegel, and Crockett explain that research in moral psychology has traditionally investigated three dimensions of moral cognition: moral decision making, moral judgment, and moral inference. Moral decision making is understood as "how people make decisions that affect the welfare of others" (Yu et al. 2019, p. 410). Moral judgment is described as "how people make judgments about the moral appropriateness of actions and assign blame and punishment, or praise and reward" (Yu et al. 2019, p. 410). Moral inference refers to "how people form beliefs about the moral character of agents based on observations of morally relevant behaviors" (Yu et al. 2019, p. 410). In their study as in most, the focus is on "a particular action" (Yu et al. 2019, p. 412). For example, there is a "decider" and a "receiver" in an investigation of harm-aversion in moral decision making, wherein the participants make choices between different amounts of money and different numbers of painful electric shocks (Yu et al. 2019, p. 413). Even moral intuitionists concentrate on judgments about single events. Consider the classic trolley dilemma, wherein five people will be killed unless one either flips a switch, which would turn the trolley onto another track and kill only one person, or pushes a large man off the bridge, thereby killing the man but stopping the trolley from killing the five (Liao 2016, p. 23). In these types of studies, subjects are typically given moral dilemmas, and their reactions, decisions, and even brain images are used to draw conclusions about how and why people make moral judgments in the ways that they do. Subjects are asked, for instance, would you help this person in this particular situation?

Research in social psychology on the role of moral intuition remains wedded to responses to particular moral dilemmas. This is important work, but it does not address what Christian ethicists describing cultures of sin have recognized: that we can appear to be doing good and still be participating in patterns, conversations, and communities that perpetuate injustice. What matters is not only the obvious harm done to one person by another. What requires sustained attention is the culture that enables the wrongdoing in the first place. Entering the province of moral intuitions brings us closer to recognizing the significance of the unconscious dimensions of morality and the importance of moral vision.

\section{Igniting the Moral Imagination with Story}

My argument is that where Christian ethicists are needed at this moment is in the murky province of moral vision. McCabe and Massingale demonstrate that we do not always or often see racism and sexism because we live it daily. The same might be said of a range of other injustices, sins of commission and omission. William Spohn defined moral perception as "the active ability to grasp the human significance of a situation, to be receptive to its significance for benefiting or harming people" and observed that it depends on affective skills that we bring to human interactions (Spohn 2003, p. 92). We must be able to recognize injustice in order to respond. Moral perception requires attention, Spohn tells us, which entails seeing the situation as it is rather than how I want it to be. Developing a just moral vision is not "merely replacing one point of view with a more adequate one but becoming able to see the invisible" (Spohn 2003, p. 107). Iris Murdoch referred to this concept as moral insight or moral vision, which is "shown in [people's] mode of speech or silence, their choice of words, their assessments of others, their conception of their own lives, what they think attractive or praiseworthy, what they think funny" (Murdoch 1998, pp. 80-81). Haidt and Joseph link moral perception to being virtuous: "To possess a virtue is to have extended and refined one's abilities to perceive morally relevant information so that one is fully responsive to the local sociomoral context." To possess a virtue is to have a "perceptual sensitivity" (Haidt and Joseph 2008, p. 386). One step beyond moral perception, I argue, is moral imagination, which must see the world as it is and also conceive of the world otherwise than it is now. 
In her book Prophets of the Posthuman: American Fiction, Biotechnology, and the Ethics of Personhood, Christina Bieber Lake defines the moral imagination as "the faculty engaged in interpreting and valuing the facts of the world as they appear to the moral actor" (Lake 2013, p. 32). Lake explains that we do not make moral choices simply based on empirically verifiable facts because two people who have the same facts may still interpret and respond to a situation very differently. Rather, we make choices according to a particular vision of the world, which she also calls a perspective or a Gestalt. If our moral imagination is that through which we interpret the facts of the world, much like the moral vision and perception that Spohn and Murdoch describe, then it is critical that we attend to developing and expanding our own and others' moral imaginations. The moral imagination can enable us to view the world otherwise than it is, thereby adding new dimension to our moral vision, if we allow stories to illuminate what we otherwise do not see. Lake understands the moral imagination to be doing the daily work of translating experience into meaning and meaning into moral decisions. The imagination and its translations are, she says, "affected by values we do not even know we possess and by beliefs we thought we had abandoned" (Lake 2013, p. 34). One could expect Heyer, McCabe, or Massingale to say the same.

The primary purpose of this essay is to call attention to the need to confront the unconscious dimensions of the moral life, which are harmful, pervasive, and easily overlooked. Much more work needs to be done on how best to address this dimension of morality. The modest suggestion I offer here for igniting moral imaginations is story. ${ }^{6}$ Stories encompass "the nonrational depths needed to move people to see social reality differently" (Massingale 2015a, p. 67). Not just any story will do; just as intuitions can be misshapen by cultures of sin, so stories can participate or reflect the same sinful cultures and function to reinforce them. We need prophetic stories that reveal the sins that we cannot see and that shape or reform distorted moral vision in new and counter-cultural ways. Story is crucial-the written word, but also story as it appears in films, in discussions of current events, through community engagement, in dialogue with those from whom we differ. Stories should not only be read or viewed; they should be experienced in person. People need to experience the lives of those from whom they differ. This is at least one way to shape our intuitions. ${ }^{7}$

For Lake, prophetic narratives are the way into the moral imagination. As an English professor, she argues that narrative suggests the kind of selves we can be, gives outcome to ethical action, and reveals how we are embedded in communities (Lake 2013, p. 7). She relies on the stories of Nathaniel Hawthorne, Flannery O'Connor, Raymond Carver and others to "nurture, nourish, and evoke a consciousness and perception alternative to the consciousness and perception of the dominant culture around us" (Lake 2013). Murdoch lifts up parables and stories as moral guides, sources of moral inspiration that highly specific rules could not give. Jonathan Haidt and Craig Joseph similarly emphasize the importance of stories: "When we try to teach our children kindness and compassion, we commonly use stories about mean people who lack those virtues. While hearing such stories children feel sympathy for the victim and condemnation for the perpetrator." Importantly, they add, "Adults cannot create such flashes [of intuition] out of thin air; they can only put children into situations in which these flashes are likely to happen" (Haidt and Joseph 2004, p. 63). While Haidt and Joseph are encouraging stories to be part of the moral development of children, stories should be able to catalyze similar flashes of intuition in adults. Moreover, Haidt and Joseph state that children have to be in these situations. Elsewhere, they argue that "without narrative, our moral concepts would be disjointed and hard to integrate into coherent action plans," and narratives are a tool for modifying intuitions, "an indispensable part of moral education in every culture" (Haidt and Joseph 2008 , p. 390). Immersion in other people's stories can make people uncomfortable, enable them to see what they otherwise could not, and transform their moral vision. ${ }^{8}$

Consider the following story. In a Facebook post turned essay, Lori Lakin Hutcherson responds to the query of a White friend who asks for help understanding White privilege and how he is guilty of it. ${ }^{9}$ Hutcherson explains the ways that institutional racism has 
impacted her by telling stories of her own experiences from the time she was three years old through her adult life thus far. After each story, Hutcherson states that if you have never experienced what she has experienced, you have White privilege. Her stories include being the only person of her race in a class and being called out for it, being on the receiving end of the assumption that her achievements have only been due to her race, having her attendance at Harvard questioned based on her skin color, and having to grow up without role models and images in school that reflect her. Her stories are powerful and unpack White privilege better than rational, detached definitions ever could. These stories enable persons of privilege to see what they could not otherwise see, to comprehend, however incompletely, how the culture of racism operates continuously in seemingly innocuous moments.

Heyer begins her ethic of immigration with the autobiographical account of a young woman in Arizona who immigrated from Mexico when she was two years old. "A month after my high school graduation, ICE [Immigration and Customs Enforcement] agents with loaded guns, bullet-proof vests, and steel-toed boots surrounded my house and nearly pounded down my front door, demanding to see my dad and me... I fell to my knees in front of the agent and began pleading with him to let me stay, telling him I was starting college in a month on a special scholarship" (Heyer 2012, p. 1). The ICE agents would let her go if she told them where they could find her dad. Receiving a nod from her mother, she gave them this information, and her father was then arrested at work and deported. She reflects, "Was this what normal students had to sacrifice for their education?" and recalls, "I stood in complete disbelief; I had sold my own dad for an education" (Heyer 2012, p. 2). That Heyer opens her book with this story is an indication of the power of narrative. Personal experiences such as this story and the ones offered by Hutcherson reveal injustice in ways that textbook definitions cannot. These narratives have the potential to impact intuitions, evoke emotion, and reveal to privileged persons that which is virtually impossible for them to see or know.

Spohn focuses on New Testament stories, which, he says, "should shape the dispositions and identity of Christians so that they live a distinctive life of discipleship together" (Spohn 2003, p. 3). What we perceive depends on our character, and New Testament stories shape our character. Parables, such as the Good Samaritan (Luke 10: 25-37) and the Workers in the Vineyard (Matt. 20: 1-16), "crack open the settled world" (Spohn 2003, p. 104) and provide new analogies and metaphors that "disclose details and depth we had missed before" (Spohn 2003, p. 101). Importantly, the Gospels expose counterfeit norms and biases that claim to draw on the story of Jesus but cover up or perpetuate poverty, oppression, violence, and patriarchy (Spohn 2003, p. 11). For Spohn, the New Testament enables us to see analogies between the life of Jesus and our own and discern how to act both faithfully and creatively in the current situations in which we find ourselves. But before we can even act, we must see truthfully, and those who are privileged need the stories and experiences of people and places other than they own to see what they cannot and to shape their moral intuitions.

Story is merely one step toward cultivating a culture that prioritizes encounter with those from whom we differ. Jennifer Harvey uses stories in her race-conscious approach to parenting because these stories "illustrate the differences between color-blind and race-conscious parental responses" and "enable parents to imagine other practical and constructive responses they might enact with their own children in different scenarios and at various ages" (Harvey 2017, p. 19). Harvey aims to show that "another world is possible" (Harvey 2017, p. 21). The reality of moral intuitions and social sin point toward the need for multiple dimensions in the construction of learning. Teaching Christian ethics requires stories in the form of community engagement, film, literature, current events, guest speakers in the classroom, but it also requires diversifying the sources on our syllabi, diversifying faculty, and leveraging out-of-classroom opportunities for learning. Each of these activities builds stories, adds layers to existing stories, and breaks open stories 
in ways that set moral imaginations ablaze for justice. Stories enable us to see what we otherwise cannot and form our moral vision so that we can and will see what we must.

\section{Conclusions}

This paper seeks to draw attention to the unconscious dimensions of the moral life, including moral vision, moral imagination, and distorted consciousness, a province of moral theology of urgent concern. In doing so, this paper also claims that moral theology must be engaged in the task of revising conceptions of moral agency to account for the unconscious dimensions of the moral life, including moral intuitions. Pockets of scholarship have illuminated to the need to alter existing conceptions of moral agency. This essay joins with them in urging continued movement away from understanding human beings as rational, deliberate, self-aware decision makers, but it does so through scholarship in moral psychology, which points to the need to focus on the formation of intuitions. Therefore, this paper also suggests that moral theology benefits from integrating research in other disciplines, expanding the boundaries of what has traditionally been understood to be the domain of moral theology.

Although the role of emotions in moral decision making has long been a topic of scholarly debate, moral theologians continue to treat human beings primarily as rational decision makers who make conscious choices and form themselves in deliberate ways. Ignoring the unconscious province of the moral life, moral theology inadequately attends to the problem of human captivity to cultures of sin, wherein persons may act in seemingly acceptable ways and yet perpetuate injustice. In joining intuitionist theory with Christian ethics, one sees that intuitions play a central role in the social sins such as racism and sexual violence. Our intuitions can be useful, but they can also be highly problematic. This essay concludes with the modest suggestion that immersion in stories-primarily the stories of the marginalized-is one avenue for forming moral intuitions, drawing us out of our narrow perspective and limited formation and into others' worlds.

Funding: This research received no external funding.

Institutional Review Board Statement: Not applicable.

Informed Consent Statement: Not applicable.

Data Availability Statement: Not applicable.

Acknowledgments: I am grateful to my graduate assistant, Josh Sturgeon, for his assistance editing this paper.

Conflicts of Interest: The author declares no conflict of interest.

\section{Notes}

1 (Massingale 2015a, pp. 62-63) Massingale has identified two schools of thought regarding formation of conscience. One approach conceives of conscience formation as "information gathering," while the other views it as a "process of character development" or moral maturation. The "information gathering" approach to conscience formation prepares conscience to confront a particular moral dilemma by collecting information relevant to the situation at hand. This approach considers a number of sources of moral wisdom, especially the hierarchical magisterium, in order to illuminate and guide conscience. The second approach to conscience formation focuses not on a particular action or judgment to be made, but on cultivating a person's moral maturity and integrity. The difference, notes Massingale, is between striving for an "upright moral decision" in the former, and a "well-rounded decision maker" in the latter.

2 In this paper, "unconscious" means nonconscious or unaware. Bryan Massingale describes "unconscious racial bias" using Charles Lawrence's definition of "unconscious": "mental processes of which we have no awareness that affect our actions and the ideas of which we are aware." Lawrence describes racism as unconscious because it "is much more complex than either the conscious conspiracy of a power elite or the simple delusion of a few ignorant bigots. It is a part of our common historical experience and, therefore, a part of our culture. It arises from the assumptions we have learned to make about the world, ourselves, and others as well as from the patterns of our fundamental social activity (Lawrence 1987, pp. 329-30). 
3 I use the phrases "moral vision" and "moral perception" interchangeably in this paper because I am drawing on thinkers, such as William Spohn and Iris Murdoch, who use one or the other phrase to describe similar concepts.

4 Although Haidt's work is intended to identify commonalities across cultures with respect to morality, he is focused on the culture wars between liberals and conservatives in the United States and how each group makes moral judgments distinct from the other. My research in this paper is limited to a Western context. I am grateful for a reviewer's question about whether being raised in other cultures would impact one's moral intuitions. Surely it would, and I look forward to addressing this in future research.

5 Moral psychologist Jesse Prinz believes Haidt overstates the case for reason as post hoc, evidenced by the fact that people can be persuaded to change their moral judgments based on rational arguments and suggests that reason and emotion are less distinct than Haidt implies (Prinz 2016, p. 64). James Woodward, a philosopher of psychology, argues that emotion and reason are not sharply distinct but related, a theory he calls "integrated nondichotomy." (Woodward 2016, p. 87). Psychologist Paul Bloom views the relationship between emotion and judgment as less linear, noting that emotions may cause judgments but judgments may also cause emotions; moreover, emotions may be preceded by a sophisticated analysis of the situation (Bloom 2012, pp. 84-85).

6 See (Nussbaum 2001). Martha Nussbaum has written about both emotions and narratives. There are important differences between her account of emotions and moral psychologists' accounts of moral intuitions. Nussbaum contends that emotions "have rich cognitive/intentional content" and "involve judgments about important things." There is a level of awareness in her understanding of emotions that moral intuition lacks. Nussbaum also claims that moral philosophy ought to incorporate literature and other works of art, which deepen self-understanding. She argues that philosophical questions arise in works of literature and are best discussed in conjunction with the concrete lives that unfold therein. I agree, but the work that I believe story should do is not turn us inward, towards ourselves, but outward, towards what is different and other.

7 It is undoubtedly the case that many of our stories are themselves products of cultures of sin. This reinforces the need to ask whose stories and which storytellers? Additionally, part of the work of stories is shaping us to be listeners. Stories only benefit us if we are willing to listen to them and to those telling them. Advocating for the importance of stories is simultaneously to advocate for deep, genuine listening.

8 Paul J. Zak, professor of economics, psychology, and management at Claremont Graduate University researches the impact of stories on empathy. See (Zak 2013). See also (Lehnen 2016).

9 (Hutcherson 2017) My synopsis here is inadequate at best. Hutcherson's own words are powerful and should be read widely.

\section{References}

Applebaum, Barbara. 2010. Being White, Being Good: White Complicity, White Moral Responsibility, and Social Justice Pedagogy. Lanham: Lexington Books.

Bloom, Paul. 2012. Moral Nativism and Moral Psychology. In The Social Psychology of Morality. Edited by Mario Mikulincer and Phillip R. Shaver. Washington, DC: American Psychological Association, pp. 71-89.

Carter, J. Kameron. 2019. How a Courtroom Ritual of Forgiveness Absolves White America. Religion News Service. Available online: https:/ /religionnews.com/2019/10/04/how-a-courtroom-ritual-of-forgiveness-absolves-white-america/ (accessed on 11 August 2019).

Catechism of the Catholic Church, 2nd ed. 1992. Available online: https://www.vatican.va/archive/ENG0015/_INDEX.HTM (accessed on 18 August 2019).

Cillizza, Chris. 2019. Three Theories on Why Donald Trump's Lies Don't Seem to Faze Him (Or His Supporters). Available online: https:/ /www.cnn.com/2019/04/03/politics/donald-trump-lies-reasons/index.html (accessed on 19 August 2019).

Cushman, Fiery, and Joshua Greene. 2012. The Philosopher in the Theater. In The Social Psychology of Morality. Edited by Mario Mikulincer and Phillip R. Shaver. Washington, DC: American Psychological Association, pp. 33-50.

Ditto, Peter H., and Brittany Liu. 2012. Deontological Dissonance and the Consequentialist Crutch. In The Social Psychology of Morality. Edited by Mario Mikulincer and Phillip R. Shaver. Washington, DC: American Psychological Association, pp. 51-67.

Fredericks, Sarah E. 2019. Climate Apology and Forgiveness. Journal of the Society of Christian Ethics 39: 143-59. [CrossRef]

Greene, Joshua D. 2016. Beyond Point-and-Shoot Morality: Why Cognitive (Neuro)Science Matters for Ethics. In Moral Brains: The Neuroscience of Morality. Edited by S. Matthew Liao. New York: Oxford University Press, pp. 119-49.

Haidt, Jonathan. 2001. The Emotional Dog and Its Rational Tail: A Social Intuitionist Approach to Moral Judgment. Psychological Review 108: 814-34. [CrossRef] [PubMed]

Haidt, Jonathan, and Craig Joseph. 2004. Intuitive Ethics: How Innately Prepared Intuitions Generate Culturally Variable Virtues. Daedalus 133: 55-66. [CrossRef] 
Haidt, Jonathan, and Craig Joseph. 2008. The Moral Mind: How Five Sets of Innate Intuitions Guide the Development of Many Culture-Specific Virtues and Perhaps Even Modules. In The Innate Mind, Volume 3: Foundations and the Future. Edited by Peter Carruthers, Stephen Laurence and Stephen Stich. New York: Oxford University Press, p. 3.

Harvey, Jennifer. 2017. Raising White Kids: Bringing Up Children in a Racially Unjust America. Nashville: Abingdon Press.

Heim, Maria, and Anne Monius. 2014. Recent Work in Moral Anthropology. Journal of Religious Ethics 42: 385-92. [CrossRef]

Heyer, Kristin E. 2012. Kinship across Borders: A Christian Ethic of Immigration. Washington, DC: Georgetown University Press.

Hutcherson, Lori Lakin. 2017. My White Friend Asked Me on Facebook to Explain White Privilege. I Decided to Be Honest. Yes! Available online: https: / www.yesmagazine.org/people-power/my-white-friend-asked-me-on-facebook-to-explain-whiteprivilege-i-decided-to-be-honest-20170809 (accessed on 10 August 2019).

Jenkins, Willis. 2013a. Atmospheric Powers, Global Injustice, and Moral Incompetence: Challenges to Doing Social Ethics from Below. Journal for the Society of Christian Ethics 34: 65-82. [CrossRef]

Jenkins, Willis. 2013b. The Future of Ethics: Sustainability, Social Justice, and Religious Creativity. Washington, DC: Georgetown University Press.

Jonas, Hans. 1973. Technology and Responsibility: Reflections on the New Tasks of Ethics. Social Research: An International Quarterly 40: 31-54.

Kendi, Ibram X. 2019. How to Be an Antiracist. New York: One World.

Kessler, Glenn, Salvador Rizzo, and Meg Kelly. 2019. President Trump Has Made 12,019 False or Misleading Claims over 928 Days. Available online: https:/ / www.washingtonpost.com/politics/2019/08/12/president-trump-has-made-false-or-misleadingclaims-over-days/ (accessed on 19 August 2019).

Kohlberg, Lawrence. 1969. Stage and Sequence: The Cognitive-Developmental Approach to Socialization. In Handbook of Socialization Theory and Research. Edited by D. A. Goslin. Chicago: Rand McNally, pp. 347-480.

Lake, Christina Bieber. 2013. Prophets of the Posthuman: American Fiction, Biotechnology, and the Ethics of Personhood. Notre Dame: University of Notre Dame Press.

Lawrence, Charles. 1987. The Id, the Ego, and Equal Proection: Reckoning with Unconscious Racism. Stanford Law Review 39: 317-88.

Lehnen, Christine. 2016. Exploring Narratives' Powers of Emotional Persuasion through Character Involvement: A Working Heuristic. The Journal of Literary Theory 10: 247-70. [CrossRef]

Liao, S. Matthew. 2016. Morality and Neuroscience: Past and Future. In Moral Brains: The Neuroscience of Morality. Edited by S. M. Liao. New York: Oxford University Press, pp. 1-42.

Massingale, Bryan N. 2010. Racial Justice and the Catholic Church. Maryknoll: Orbis Books.

Massingale, Bryan. 2015a. Conscience Formation and the Challenge of Unconscious Racial Bias. In Conscience and Catholicism: Rights, Responsibilities, and Institutional Responses. Edited by David E. DeCosse and Kristin E. Heyer. Maryknoll: Orbis Books, pp. 53-68.

McCabe, Megan K. 2018. A Feminist Catholic Response to the Social Sin of Rape Culture. Journal of Religious Ethics 46: 635-57. [CrossRef]

McKearny, Patrick. 2016. The Genre of Judgement: Description and Difficulty in the Anthropology of Ethics. Journal of Religious Ethics 44: 544-73. [CrossRef]

McRorie, Christina. 2016. Rethinking Moral Agency in Markets: A Book Discussion on Behavioral Economics. Journal of Religious Ethics 44: 195-226. [CrossRef]

Murdoch, Iris. 1998. Vision and Choice in Morality. In Existentialists and Mystics: Writings on Philosophy and Literature. Edited by P. Conradi. New York: Allen Lane The Penguin Press, pp. 76-98.

Nussbaum, Martha C. 2001. Upheavals of Thought: The Intelligence of the Emotions. New York: Cambridge University Press.

Prinz, Jesse. 2016. Sentimentalism and the Moral Brain. In Moral Brains: The Neuroscience of Morality. New York: Oxford University Press, pp. 45-73.

Schweiker, William. 1995. Responsibility and Christian Ethics. Cambridge: Cambridge University Press.

Spohn, William C. 2003. Go and Do Likewise: Jesus and Ethics. New York: Continuum.

Sullivan, Shannon. 2014. The Hearts and Guts of White People: Ethics, Ignorance, and the Physiology of White Racism. Journal of Religious Ethics 42: 591-611. [CrossRef]

United States Conference of Catholic Bishops. 2019. Forming Conscience for Faithful Citizenship: A Call to Political Responsibility from the Catholic Bishops of the United States. Available online: https:/ /www.usccb.org/issues-and-action/faithful-citizenship/ upload/forming-consciences-for-faithful-citizenship.pdf (accessed on 11 August 2019).

Vasko, Elisabeth. 2015. Beyond Apathy: A Theology for Bystanders. Minneapolis: Fortress Press.

Woodward, James. 2016. Emotion versus Cognition in Moral Decision-Making. In Moral Brains: The Neuroscience of Morality. Edited by S. M. Liao. New York: Oxford University Press, pp. 87-116.

Yu, Hongbo, Jenifer Z. Siegel, and Molly J. Crockett. 2019. Modeling Morality in 3-D: Decision-Making, Judgment, and Inference. Topics in Cognitive Science 11: 409-32. [CrossRef] [PubMed]

Zak, Paul J. 2013. How Stories Change the Brain. Greater Good Magazine: Science-Based Insights for Meaningful Life. Available online: https://greatergood.berkeley.edu/article/item/how_stories_change_brain (accessed on 7 February 2021). 